\section{Documentation in the Patient's Medical Record by Clinical Pharmacists in a Canadian University Teaching Hospital: Correction}

A recent article ${ }^{1}$ in the Canadian Journal of Hospital Pharmacy concerned documentation by clinical pharmacists in patients' medical records. As a result of errors in processing the manuscript for publication, the definition for "minimal documentation" was worded incorrectly (with incorrect data being reported for this category of results), an incorrect version of Figure 1 was published, and some text was omitted from the paragraph describing strengths and limitations of the study. We sincerely apologize for any inconvenience caused by these errors. Corrections are provided here.

ABSTRACT_Results: The opening sentences of this paragraph should read as follows (correction indicated in bold):

A total of 779 patient charts from 4 inpatient units were included in the analysis. Of these, $131(\mathbf{1 6 . 8} \%)$ were considered to have minimal documentation (at least 1 suggestion or verbal order without a note in the progress section), $432(55.5 \%)$ had sufficient documentation (at least 1 note written during the patient's hospitalization), and 81 $(10.4 \%)$ had extensive documentation (appropriate number of notes in relation to duration of hospitalization).

\section{METHODS—Outcomes (paragraph 2):}

The definition of minimal documentation should read as follows, with omission of reference to a composite end point:

"Minimal" documentation was defined as at least 1 suggestion or verbal order recorded in the prescription section of the patient's medical record, without any note in the progress section of the patient's medical record.

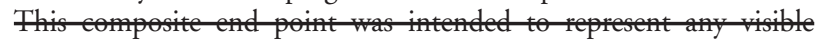
of t t t t

\section{RESULTS-paragraph 1:}

The summary statement of results and updated table should read as follows (corrections indicated in bold):

The numbers of patients' medical records with minimal, sufficient, and extensive documentation were 131 (16.8\%), 432 (55.5\%) and $81(10.4 \%)$, respectively (Table 1$)$.
Table 1. Level of Documentation and Interventions Included in Patients' Medical Records

\begin{tabular}{|c|c|c|}
\hline \multirow{2}{*}{$\begin{array}{l}\text { Characteristic } \\
\text { Level of documentationt }\end{array}$} & \multicolumn{2}{|c|}{$\begin{array}{l}\text { No. (\%) of Records* } \\
\quad(n=779)\end{array}$} \\
\hline & & \\
\hline Extensive & 81 & $(10.4)$ \\
\hline Sufficient & 432 & $(55.5)$ \\
\hline Minimal & 131 & \\
\hline \multicolumn{3}{|c|}{$\begin{array}{l}\text { Intervention documented in the prescription section } \\
\text { Verbal orders }\end{array}$} \\
\hline Records with $\geq 1$ verbal order & 142 & $(18.2)$ \\
\hline $\begin{array}{l}\text { No. of verbal orders per record } \\
\text { (median and IQR) }\end{array}$ & 1 & $(1-2)$ \\
\hline \multicolumn{3}{|l|}{ Suggestions } \\
\hline Records with $\geq 1$ suggestion & 369 & (47.4) \\
\hline $\begin{array}{l}\text { No. of suggestions per record } \\
\text { (median and IQR) }\end{array}$ & 1 & $(1-2)$ \\
\hline Verbal orders and/or suggestions & & \\
\hline $\begin{array}{l}\text { Records with } \geq 1 \text { verbal order or } \\
\text { suggestion (or both) }\end{array}$ & 426 & $(54.7)$ \\
\hline \multicolumn{3}{|c|}{$\begin{array}{l}\text { IQR }=\text { interquartile range. } \\
\text { *Except where indicated otherwise. } \\
\text { †Extensive documentation was defined as presence of } \geq 1 \text { admission, } \\
\text { follow-up, or discharge note for hospital stays } \leq 2 \text { days; an admission } \\
\text { note and a discharge note for hospital stays of } 3-6 \text { days; or an } \\
\text { admission note, a follow-up note, and a discharge note for hospital } \\
\text { stays } \geq 7 \text { days. Sufficient documentation was defined as presence of } \\
\geq 1 \text { note in medical section of patient's medical record, regardless of } \\
\text { the patient's length of stay in hospital. Minimal documentation } \\
\text { was defined as } \geq 1 \text { suggestion or verbal order recorded in the } \\
\text { prescription section of the patient's medical record, without } \\
\text { any note in the progress section of the patient's medical record }\end{array}$} \\
\hline
\end{tabular}

A corresponding summary statement of results also appears in the first paragraph of the Discussion, where the same correction is required (i.e., number of records with minimal documentation was $131[16.8 \%])$.

The correct version of Figure 1 (next page) details the study results according to clinical unit of the hospital. 


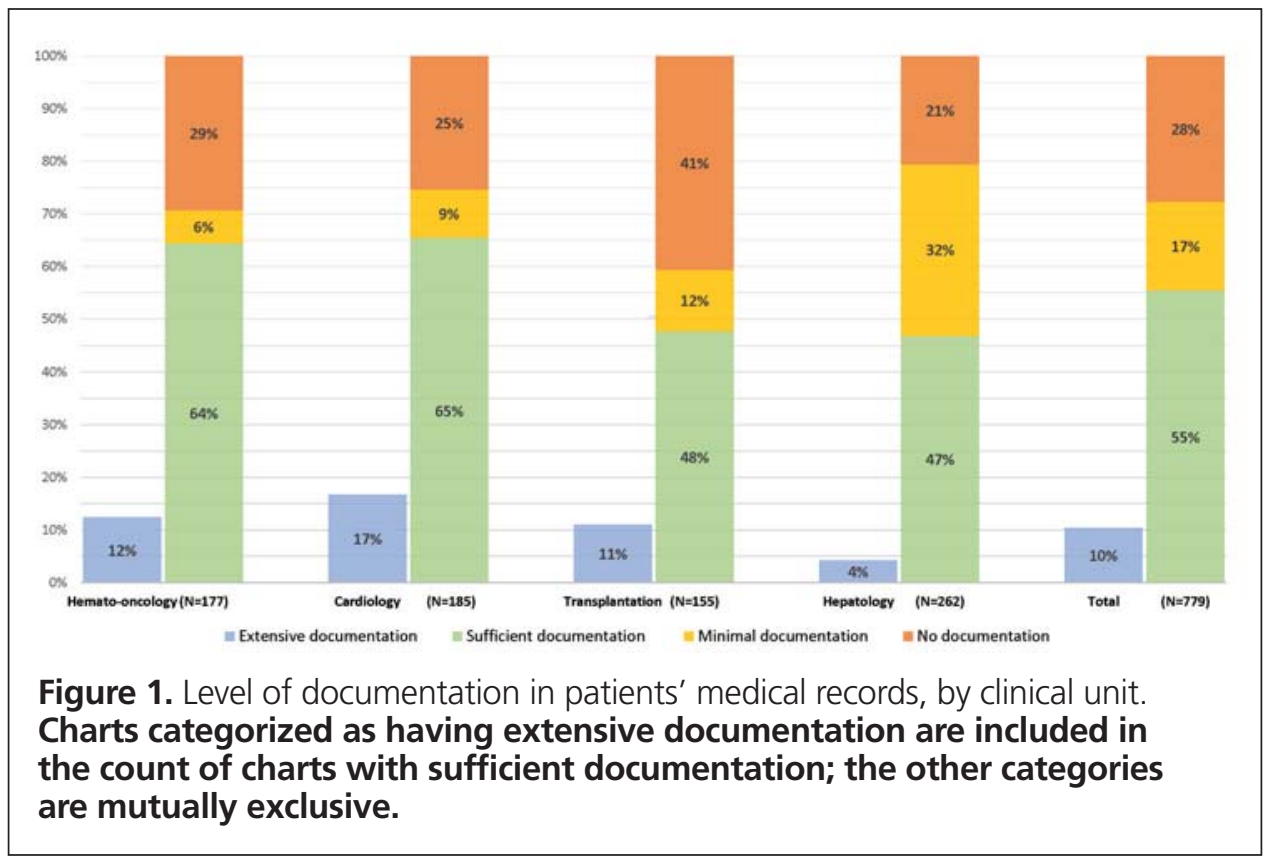

\section{DISCUSSION—Strengths and Limitations}

Some text was inadvertently omitted from the paragraph describing strengths and limitations of the study. The complete paragraph is presented here:

This study had both strengths and limitations. The data in this study were obtained retrospectively and objectively thereby avoiding selfreported documentation like others studies. ${ }^{2,3}$ Collection of the data by 2 pairs of students may have introduced observation bias. To limit such bias, $10 \%$ of all records were double-checked and corrected, if appropriate, by the other team of students. The patients' medical records were handwritten and although the observers were vigilant, some data may have been missed (e.g., if pharmacists did not identify themselves adequately in the record or if the quality of the handwriting was poor). However, the large number of records analyzed (with exclusion of only 1 record) may have compensated for these limitations. Another limitation was the absence of testing for interindividual variability between clinical pharmacists. However, the goal of the study was not to identify differences among pharmacists, but rather to determine tendencies and trends, in order to ameliorate the practice of a group of pharmacists. Only 4 types of specialized clinical units were included in the study, which might have affected the external validity in relation to less specialized clinical units (e.g., internal medicine, emergency and other nonteaching hospitals with fewer resources. These specialized clinical units were chosen for 3 reasons: ease of retracing patients followed by pharmacists, presence of students for 2 of every 4 months, and presence of the clinical pharmacist on the unit every weekday during the duration of the study. Because the objective of the study was to quantify pharmacists' documentation in patients' medical records, the impact of pharmacists' notes on patient care could not be evaluated. Although the acceptance rate was unknown, the clinical pharmacists were proactive in proposing drug changes either through verbal orders or suggestions in more than $50 \%$ of the records. Finally, the statistical analysis did not control for multiplicity.

\section{References}

1. Adam JP, Trudeau C, Pelchat-White C, Deschamps ML, Labrosse P, Langevin MC, et al. Documentation in the patient's medical record by clinical pharmacists in a Canadian university teaching hospital. Can J Hosp Pharm. 2019;72(3):194-201.

2. Condren ME, Haase MR, Luedtke SA, Gaylor AS. Clinical activities of an academic pediatric pharmacy team. Ann Pharmacother. 2004;38(4):574-8. [reference was numbered as 15 in published article]

3. Lada P, Delgado G Jr. Documentation of pharmacists' interventions in an emergency department and associated cost avoidance. Am J Health Syst Pharm. 2007;64(1):63-8. [reference was numbered as 16 in published article] 